\title{
Ecuador en el dilema de una democracia de los "ismos"
}

\section{Ecuador in the dilemma of a democracy of the "isms"}

\author{
Wilson Benavides Vásquez
}

Recepción: 28-05-2020

Aceptación: 24-07-2020

\section{Resumen}

Este artículo busca poner en cuestión la idea de que la democracia en nuestro país se sustenta únicamente en su sistema de partidos. Sostiene, por el contrario, que a la luz de la experiencia concreta, son los líderes y los grupos de presión de distinto tipo, los que han consolidado o debilitado este régimen político, al menos en los últimos 18 años durante los gobiernos de Lucio Gutiérrez (2002-2005), Rafael Correa (20072017) y Lenin Moreno (2017-2020). Esto pone en relación directa dos fenómenos, que gran parte de la literatura académica y de los propios actores políticos creían ya superados. El populismo y el corporativismo, pese a la desazón de muchos, hoy están más vigentes que nunca, tejiendo la argamasa de nuestra cultura política. A manera de hipótesis, sostengo que ambos fenómenos constituyen un "conjunto de subjetividades, significados y prácticas" (Ramírez, 2003) a través del que se expresa la democracia en Ecuador en la coyuntura analizada.

Palabras clave: populismo, corporativismo, democracia, cultura política, partidismo.

\begin{abstract}
This article seeks to put into question the idea that democracy in our country is based only on their party system. It argues, to the contrary, that in the light of the concrete experience, the leaders and pressure groups of different kinds are the ones who have strengthened or weakened this political regime, at least in the last 18 years during the government of Lucio Gutierrez (2002-2005), Rafael Correa (2007-2017) and Lenin Moreno (2017-2020). This puts in direct relation the two phenomena that much of the academic literature and the political actors themselves believed to have been overcome. The populism and corporatism, despite the discontent of many, are more prevalent today than ever before, weaving the mortar of our political culture. As a hypothesis, I argue that both phenomena constitute a "set of subjectivities, meanings and practices" (Ramírez, 2003) through which it expresses democracy in Ecuador at the analyzed
\end{abstract} juncture.

Key Words: Populism, corporatism, democracy, political culture, partisanship. 


\section{Introducción}

$\mathrm{D}$ esde 1979 hasta el derrocamiento de Abdalá Bucaram en 1997¹ la modernización del sistema político iba tomando forma desde las perspectivas institucionalistas de la ciencia política y de los líderes que encabezaron el retorno a la democracia quienes -entusiastas- promovían el fortalecimiento de los partidos como condición suficiente para la consolidación de este régimen político. Los enfoques culturalistas, en cambio, se centraron en analizar la cultura política de los sectores subalternos, en los que se apalancaba el populismo, fenómeno que durante prácticamente la mitad del siglo XX ejerció su influencia a través del cinco veces presidente, José María Velasco Ibarra, y posteriormente con los líderes de Concentración de Fuerzas Populares (CFP) y del Partido Roldosista Ecuatoriano (PRE).

Años más tarde, el culturalismo fue seducido -teórica y políticamente- por la irrupción en el escenario nacional de la Confederación de Nacionalidades Indígenas del Ecuador (CONAIE) en 1990 ante los intentos de implementar en nuestro país un modelo neoliberal. A esta realidad, la visión institucionalista respondió con la teoría de la gobernabilidad democrática ${ }^{2}$.

Entre 1997 y 2007, sin embargo, la crisis política ${ }^{3}$ gestada -en partedesde los propios partidos que capitalizaron la acción de los movimientos sociales liderados por la CONAIE, provocó que en esa década el Ecuador

\footnotetext{
1 Las protestas contra Bucaram iniciaron el 05 de febrero de 1997 con una huelga nacional convocada por el Frente Unitario de Trabajadores (FUT) a la que se sumó la Confederación de Nacionalidades Indígenas del Ecuador (CONAIE) y otros movimientos sociales agrupados en el Frente Patriótico de Defensa del Pueblo que rechazaron el fallido intento del entonces presidente de eliminar el subsidio al gas de uso doméstico y los escandalosos hechos de corrupción como el caso "mochila escolar" y el manejo de las aduanas, entre otros, que le significaron una sentencia por peculado. Bucaram fue reemplazado por su vicepresidenta Rosalía Arteaga y posteriormente por el entonces presidente del Congreso Nacional, Fabián Alarcón.

2 Este discurso emerge en el contexto del descubrimiento de que la sociedad ecuatoriana no era ni contractual ni plenamente racional. Postula que la causa de la inestabilidad política es "la arquitectura institucional del sistema, que requiere una reforma profunda" (Andrade, 2003:393-395).

3 En 1988, el Centro Andino de Acción Popular (CAAP) introduce en el pensamiento político ecuatoriano el concepto de crisis desde dos perspectivas que serían dominantes en los años 90. Por un lado, como debilidad del sistema político; y por otro, como crisis de representación. Desde ambas ópticas, la crisis política, es para el CAAP, una "debilidad estructural del Estado y del sistema político-democrático, que se traduce (en una) incapacidad de los actores socio-políticos para generar propuestas alternativas globalizantes" (Andrade, 2009: 107).
} 
tenga siete presidentes ${ }^{4}$ y se vayan creando las condiciones para el colapso del sistema de partidos que se concretó tras la caída de Lucio Gutiérrez en 2005, con la consigna ciudadana del "fuera todos".

El derrocamiento de Gutiérrez (2005) (quien fue deshabilitado por los partidos para participar en las elecciones de 2006) catapultó el surgimiento de un periodo inédito de estabilidad política liderado por una sola fuerza partidista que gobernó el país por una década (2007-2017) con altos precios del petróleo e ingente obra pública, pero bajo la influencia de un liderazgo carismático con tintes autoritarios y tecnocráticos (De la Torre, 2015) que terminó cooptando todas las funciones del Estado, poniendo en entredicho la libertad de prensa y cuyo gobierno no estuvo exento de graves hechos de corrupción ${ }^{5}$. En los comicios generales de 2017, sin embargo, el Ecuador optó por la continuidad de ese proyecto en la figura de Lenin Moreno, quien una vez en el poder, marcó distancias con su antecesor, provocando una implosión interna mediante un parricidio político (Burbano de Lara, 2017).

Los "ismos" de la democracia ecuatoriana han sido desarrollados conceptualmente de forma desigual. Mientras el populismo cuenta con una extensa bibliografía, el corporativismo, en cambio, es aludido de manera bastante marginal. Al populismo se lo ha conceptualizado de forma paradojal tanto como una patología (Ulloa, 2017) cuanto como una expresión de la democracia (De la Torre, 2008). El corporativismo, en cambio, es más bien un término descriptivo para ciertos actores específicos (Verdesoto, 1984; Pachano, 2007) que -sin embargo- no alcanza -en buena parte de la bibliografía- a

\footnotetext{
4 A Bucaram lo sucedió su vicepresidenta Rosalía Arteaga que estuvo menos de una semana en el cargo, hasta que finalmente asumió la Presidencia el entonces titular del Congreso Nacional, Fabián Alarcón. A Jamil Mahuad lo reemplazó durante pocas horas un triunvirato integrado por Antonio Vargas (presidente de la CONAIE); Carlos Solórzano, (ex presidente de la Corte Suprema de Justicia); y el general Carlos Mendoza, (jefe del Comando Conjunto de las FF.AA.) que fue rápidamente disuelto dando paso a la sucesión constitucional en la figura de su vicepresidente, Gustavo Noboa. Lucio Gutiérrez, fue reemplazado por su vicepresidente, Alfredo Palacio.

5 El Caso Sobornos surgió luego de una publicación de prensa digital denominada "Arroz Verde" que denunció que empresas privadas entregaron dinero al gobierno de Correa a cambio de contratos de obra pública. Fue conocido por los medios como el "juicio del siglo" y al momento de escribir este artículo el ex presidente y otros ex altos funcionarios fueron condenados -en primera instancia- por el delito de cohecho, y la suspensión de sus derechos políticos por 25 años. A este caso se sumó a inicios de 2018 el caso Odebrecht que afectó a varios gobiernos de América Latina. En Perú, renunció el presidente y fue reemplazado por el segundo mandatario. En Ecuador, fue separado el vicepresidente Jorge Glas, quien cumple una sentencia de 6 años por asociación ilícita.
} 
constituirse en un fenómeno consustancial a la democracia.

Este artículo se desmarca del relato aleccionador que mira a este régimen político exclusivamente desde sus aspectos normativos como un sistema que toda sociedad "civilizada" está predestinada a alcanzar. Busca, por el contrario, poner el foco de atención en sus manifestaciones concretas en Ecuador: populismo y corporativismo, fenómenos que en la práctica ponen en jaque el monopolio de la representación (Pachano, 2007) asignado por el diseño institucional a los partidos.

Para analizar la presencia de ambos fenómenos en la cultura política ecuatoriana comparo los tres gobiernos de los últimos 18 años: Lucio Gutiérrez (2002-2005); Rafael Correa (2007-2017) y Lenín Moreno (2017-2020). Narrativamente, el texto está divido en introducción, estado de la cuestión, análisis de casos y conclusiones.

\section{Estado de la cuestión}

\section{Cultura política}

Dos temas atraviesan profundamente la bibliografía de la cultura política ecuatoriana desde mediados del siglo XX. Uno, la incorporación de los sectores populares (pueblo) al sistema político y; dos, la cuestión indígena (clivaje étnico) y en menor medida, el clivaje regional ${ }^{6}$.

Ambas cuestiones (sectores subalternos y clivajes) respondieron, en su orden, a la aparición de dos fenómenos: el populismo (De la Torre, 2008 y 2015; Ulloa, 2017) y el corporativismo (Verdesoto, 1984; Pachano, 2007; Moncayo, 2008; Quintero y Sylva, 2010) que se expresaban como correlato, entre otras cosas, de una inserción dislocada del Ecuador en los procesos de modernización capitalista7 (Quintero y Sylva, 2013).

\footnotetext{
6 Siguiendo a Torres (2006), quien explica para el caso latinoamericano el modelo de Seymour Martin Lipset y Stein Rokkan (1967), entiendo a los clivajes como fracturas sociales, conflictos antagónicos latentes, "líneas de ruptura y divisiones profundas y enraizadas en cada sociedad contemporánea" (Torres, 2006: 98). Pachano (2007) explica que en Ecuador la conducta rentista y ambos clivajes son "determinaciones estructurales que se manifiestan bajo diversas formas en el ámbito político, alimentando las conductas y orientaciones de los diversos actores, que se expresan en prácticas particularistas como el clientelismo y el corporativismo que invaden los espacios de representación mediante la imposición de intereses particulares (...)" (Pachano, 2007:98).
}

7 Estos autores plantean que en Ecuador se implantó un modelo de desarrollo denominado por ellos como 
Las nociones sobre cultura política enfatizan, por un lado, su dimensión ideacional y por otro, su capacidad para articular identidades colectivas. La primera perspectiva o modelo "ideacional" (Andrade, 2003) se concentró en el estudio de los discursos y los símbolos utilizados por líderes populistas (Burbano de Lara, 1998); la segunda, en cambio, abrió una interpretación pragmática que buscó entender el populismo no solo desde los liderazgos, sino también desde las prácticas que éstos despliegan y cómo son apropiadas o impugnadas por sus electorados (Menéndez Carrión, 1986; De la Torre, 2008 y 2015$)^{8}$.

Explorar la cultura política de un pueblo o grupo social implica no solo hacer referencia a las ideas y valores ya existentes sino además indagar sobre la forma cómo la gente configura la síntesis, producción, interpretación y reinterpretación de estos contenidos para resolver problemas (...) (Ramírez, 2003: 443).

En esta segunda dimensión, son centrales los trabajos sobre el CFP (Menéndez, 1986) y el PRE (Freidenberg, 2003) así como los ensayos sobre los populismos del denominado "socialismo del siglo XXI" (De la Torre, 2008 y 2015; y Ulloa, 2017).

Ambas perspectivas, sin embargo, pese a la existencia de los clivajes regionales y étnicos, insisten en una visión unitaria e indiferenciada de la cultura política como un rasgo característico de un determinado grupo social. En pocos casos, se reconoce -pero mayoritariamente en el plano descriptivola cultura política en plural, aunque ligada siempre a sectores poblacionales específicos.

Pachano (2007) se refiere a "las culturas políticas de las élites y del resto de la población en general", mientras que Verdesoto (1984) habla de los "sectores subalternos". Ambas nociones, promueven una serie de ideas,

\footnotetext{
"gamonal dependiente", que se caracterizó por la imbricación de relaciones capitalistas y precapitalistas propias del sistema hacendatario. Los clivajes étnicos y regional han sido vistos como amenazas a la unidad del Estado nacional.

8 En contra de una visión que alude a la cultura política como una instancia que no abarca la acción sino solamente las orientaciones para la misma, existe otro enfoque que pone el acento en la dimensión práctica y material de la cultura en tanto productora de significados, subjetividades y modos de hacer (Ramírez, 2003: 442).
} 
estereotipos y prejuicios sobre uno y otro sector ${ }^{9}$. Así, mientras las élites eran portadoras de una cultura política que promovía la versión liberal de la democracia, los sectores subalternos, en cambio, eran fácilmente seducidos por el populismo y por tanto, su cultura política "quedaba representada como un espacio donde abundan enclaves pre-ciudadanos, poco participativos y anti-democráticos (...)" (Ramírez, 2003: 429).

Los enfoques postmarxistas (Laclau, 2005; Hardt y Negri, 2004) cuestionan el determinismo en la conformación de los sujetos sociales cuestionando la insuficiencia de las categorías de "clase social", "pueblo" y "masa" y planteando la existencia de diferentes posiciones de sujeto que pueden articularse en lógicas equivalenciales (Laclau, 2005) o promover una construcción de lo común entre todas ellas (Hardt y Negri, 2004).

Es justamente en estos enfoques donde se sustenta la principal crítica a esta dicotomía de la cultura política ecuatoriana. Ramírez (2003) sostiene que los estudios de la cultura política en nuestro país, en su mayor parte, son de carácter ensayístico, aportan insuficiente trabajo de campo y terminan reproduciendo una concepción negativizada de la misma, porque siempre la comparan y contraponen con una cultura política democrática-occidental. Por ello, dice, la cultura política debería entenderse en plural, y no como algo dado o previamente establecido y esa pluralidad, señala, "es un elemento constitutivo de la política" (Ramírez, 2003: 445).

Esta politización de la cultura acepta que los significados y las prácticas particularmente aquellas teorizadas como marginales, críticas, oposicionales, minoritarias, residuales, emergentes, alternativas, silenciadas y otras (...) pueden ser la fuente de procesos definidos como políticos (Ramírez, 2003: 445).

Hablar de culturas políticas, dice Ramírez (2003), implica conceptua-

\footnotetext{
9 En el Ecuador, hay una contradicción y coexistencia entre dos grandes tipos de cultura política. Una, se constituía bajo el eje de la ciudadanía liberal y la democracia; la otra, en torno a la noción de "pueblo". Estas dos culturas, a su vez, aludían a dos tipos de identidades políticas, cuya contradicción hacía la vida política del país; el ciudadano de clase media y alta perteneciente a las élites; y el "pueblo"; una identidad amplia que interpelaba a las clases bajas que se constituían como sujeto de la política a través del discurso del líder populista (Andrade, 2009:126).
} 
lizarlas como "producciones discursivas y prácticas que sedimentan diversos esquemas representacionales, en estrecha correspondencia con la evolución del ámbito institucional de la política" (Ramírez, 2003: 442). Estas culturas, explica, son productoras de acción política expresada en "prácticas y discursos que inciden en la ampliación, reducción o cambio de la esfera de lo político y de las formas institucionales de hacer política" ${ }^{10}$ (Ramírez, 2003: 441 y 443).

\section{Populismo}

Unos estudios de los populismos latinoamericanos (Perón en Argentina; Vargas en Brasil; Velasco Ibarra en Ecuador, entre otros) explican su aparecimiento como consecuencia del paso de una sociedad tradicional a una moderna, caracterizado por los procesos de urbanización y la incorporación de nuevos sectores subalternos a los sistemas políticos, que eran justamente el caldo de cultivo donde se apalancaba este fenómeno (Quintero y Sylva, 2013; Menéndez, 1986).

Otras explicaciones, más cercanas a las perspectivas postmarxistas, miran al populismo como un discurso que divide a la sociedad en dos campos antagónicos y es capaz de definir y cristalizar identidades políticas (Laclau, 2005). Una tercera perspectiva, entiende este fenómeno como una estrategia política para la toma y ejercicio del poder (Weyland en De la Torre, 2008).

En todos estos enfoques, sin embargo, subyacen dos ideas de fondo. 1) Si el populismo origina o más bien es el resultado de las crisis institucionales y 2) Si este fenómeno democratiza la sociedad o, por el contrario, legitima el autoritarismo.

Desde una perspectiva histórica, Moncayo (2008) recuerda que en Ecuador han convivido al menos dos tipos de democracia. Por un lado, la democracia de élite y por otro, la democracia de masas. El primero, dice, "estuvo vigente hasta el gobierno de Arroyo del Río, mientras que el segundo

10 Lo cultural es político porque los significados son constitutivos de procesos que implícita o explícitamente buscan redefinir las relaciones de poder. Las culturas políticas se constituyen en el dominio de las prácticas e instituciones, esculpidas de la totalidad de la realidad social, que históricamente han pasado a ser consideradas como propiamente políticas, en la misma forma en que otros dominios son vistos como propiamente 'económicos', 'culturales' o 'sociales'” (Álvarez et. al, en Ramírez, 2003: 444, 445). 
emergió con la irrupción de las masas en el escenario electoral en 1931, 1933 y 1944 cuando se proclamó vencedor" (Ibid: 72-73).

Este autor explica que la diferencia entre la concepción liberal y elitista de la democracia por un lado y la concepción caudillista o cesarista por otro, no reside en que la primera excluya al pueblo y la segunda lo incluya, sino en el tipo de superioridad que rige.

Los liberales son partidarios de un gobierno representativo, mientras que los populistas de un gobierno unipersonal. La concepción cesarista de la democracia, borra la diferencia entre gobernantes y gobernados, mientras que la concepción liberal la mantiene (Moncayo, 2008: 76).

En el primer caso, dice Moncayo (2008), rige la "soberanía de la razón" a través del Estado de derecho, mientras que en el segundo, el pueblo se convierte en una "identidad real inmediata", encarnada en el caudillo que expresa su voluntad sin limitaciones. Explica que la diferencia entre regímenes liberales y democráticos, radica en que en los primeros rige la representación mientras que en los segundos la identidad, "una identidad directa y sin mediaciones, que surge y se expresa en actos o procesos de identificación" (Moncayo, 2008:76). Estas premisas abonan -señala- en favor de "un modelo paternalista de gobierno llamado a suplantar al pueblo "perezoso" e "indolente" y a "disciplinar" a los egoístas empresarios, preocupados solo de sus mezquinos intereses y de su propiedad". Dicho pueblo, señala, "no puede gobernarse por sí mismo y requiere de un tutor o protector hasta que adquiera la mayoría de edad o el uso de la razón" (Moncayo, 2008: 76).

En el enfoque que concibe al populismo como discurso, Ernesto Laclau (2005), analiza las demandas democráticas y populares que surgen en una sociedad y explica que las precondiciones para este fenómeno son la existencia de una frontera interna antagónica que separa al pueblo del poder; la articulación equivalencial de demandas diversas, y su unificación en un sistema estable de significación (Laclau, 2005: 99).

La articulación equivalencial de las demandas, dice, se produce mediante significantes flotantes $y$ significantes vacíos que "condensan en torno 
de sí, la significación de todo un campo antagónico (el régimen, la oligarquía, etc. para el enemigo; el pueblo, la nación, las mayorías silenciosas, para los oprimidos)" (Laclau, 2015: 114).

Un significante como "trabajadores" puede en ciertas configuraciones discursivas agotarse en un significado particularista o sectorial, mientras que en otros discursos, puede convertirse en la denominación del pueblo (Laclau, 2005: 114).

De la Torre (2008) aclara que para que las estrategias populistas funcionen deben asentarse en "formas de representación política existentes y en tradiciones discursivas disponibles". Estas estrategias, dice, se basan y hacen uso de "marcos discursivos maniqueos y de tradiciones culturales particularistas como las relaciones de reciprocidad propias del parentesco, del clientelismo y del corporativismo" (De la Torre, 2008: 26-27).

Pachano (2007) señala que entre los rasgos evidentes de la acción política ecuatoriana se destacan las prácticas clientelares que sustentan a las posiciones populistas y "se asientan en pautas de relación política al costado de las instituciones formales pero haciendo uso de ellas" (Pachano, 2007: 109).

El discurso populista se basa en la diferenciación de la sociedad en dos campos que se enfrentan de manera antagónica en una lucha entre el bien y el mal (...). Los discursos populistas generan pasiones e identidades fuertes que dividen a la sociedad entre el "pueblo virtuoso" encarnado en el líder y sus "enemigos" construidos como los "anti patria" (De la Torre, 2008: 28).

Para De la Torre (2008) el populismo oscila "entre la ambigüedad de pensamiento que imagina la sociedad como una comunidad con intereses homogéneos y la radical politización de las exclusiones" que se mantiene y reemerge mientras los Estados "continúen fallando en sus intentos por consolidar las instituciones y el Estado de derecho y no garanticen la igualdad ante la ley". Por ello, advierte, "en lugar de mostrar una modernidad basada en la idealización de los patrones occidentales, hay que analizar los rasgos de las modernidades populistas latinoamericanas" (De la Torre, 2008: 46-47). 


\section{Corporativismo}

Este es un fenómeno que al igual que el populismo se ha constituido en una forma de ejercer la democracia en Ecuador llegando a expresarse incluso en el mismo sistema de partidos (Pachano, 2007). El corporativismo "constituye un mecanismo de representación de los intereses económicos de grupos sociales organizados" que "ha bloqueado el desarrollo democrático del país al debilitar a los partidos políticos, convirtiéndolos en entidades corporativas o constituyéndolos en apéndices de los gremios" (Quintero y Sylva, 2010: 71) y se caracteriza por los siguientes rasgos:

a) Suplantar o hacer prevalecer la esfera de los intereses privados por encima de los intereses públicos o colectivos; b) Expandir/conservar las "conquistas" gremiales de sus "grupos de interés" ya obtenidas, conceptualizadas como "derechos irrenunciables"; c) Eludir el reconocimiento de los derechos y obligaciones de cada ciudadano como condición universal (de todos) por encima de sus intereses, logros y conquistas gremiales; d) Hacer prevalecer la representación de los gremios, sindicatos y corporaciones en general, por encima de los partidos políticos (Quintero y Silva, 2010: 70-71).

Con este criterio coinciden Verdesoto (1984) y Pachano (2007), para quienes este fenómeno "es una forma de presentación de los intereses sociales ante el escenario político que retrasa la constitución de un sistema político moderno y democrático" (Verdesoto, 1984:32). Pachano (2007) explica que desde el retorno a la democracia en 1979, la representación política, se expresa de manera segmentada y particularista, "tanto por la existencia de bastiones electorales regionales o locales de los partidos, como por la amplia apertura que éstos ofrecen para los intereses particulares y las formas corporativas de representación" (Pachano, 2007: 117)

Concentrados en espacios relativamente restringidos, los partidos pierden la distancia con los grupos de presión locales y asumen gran parte de sus percepciones, posiciones y demandas. Las élites locales (especialmente económicas) encuentran en los partidos a las organizaciones que pueden fortalecer, cuando no sustituir, a sus propias entidades. Los partidos entran en ese juego como condición de permanencia de sus respectivos bastiones (Pachano, 2007: 117). 
El corporativismo se convierte así, en "una forma de participación", en la que "no solo se trata de la canalización de unos intereses específicos particulares, sino de la cercanía con las personas que ejercen la representación"11 (Pachano, 2007).

La ley no regula las relaciones sociales, los pobres no pueden hacer uso de los derechos que les otorgan las constituciones. Para acceder a los servicios públicos, por ejemplo, tienen que ir en nombre de algún poderoso que los recomienda para que los funcionarios públicos los atiendan o deben suplicar un favor a un dependiente estatal. Debido a la falta de derechos ante el Estado, los pobres recurren a prácticas que aunque resultan eficaces en conseguir el bien deseado, no se basan en la ciudadanía, sino en prácticas paternalistas o en prebendas y privilegios de los grupos corporativos (De la Torre, 2015: 134).

El corporativismo de los partidos, dice Pachano (2007), refuerza el clientelismo al determinar los resultados concretos y de corto plazo, como los vínculos fundamentales entre la sociedad (regional o local) y los partidos, "que se ven obligados a mostrar rendimientos altamente valorados por la población de sus respectivos bastiones electorales, aunque eso signifique sacrificar sus lineamientos ideológicos" (Pachano, 2007: 123). Al fortalecer sus lazos con intereses de grupos específicos (y no intereses generales de la sociedad), los partidos tienden a corporativizarse y reforzar prácticas que se creían exclusivas del populismo como el clientelismo político.

En una investigación sobre las bases de apoyo electoral en Buenos Aires del Partido Justicialista argentino, Javier Auyero (2011) cuestiona los modelos de acción racional que conciben al clientelismo político como un simple "intercambio de votos por favores" y define más bien las prácticas clientelares como "elecciones prácticas aprendidas en el tiempo y experimentadas en la vida cotidiana como resolución de problemas" (Auyero, 2001: 177).

11 El constante tránsito de personas desde la representación social (gremios empresariales, sindicatos, etc.) a la representación política ha sido usual desde el retorno a la democracia llegando incluso a adscripciones explícitas por parte de autoridades en ejercicio o candidatos a un sector social determinado (Pachano, 2007: 117). 
Sostiene que estas prácticas se enmarcan en un modelo de "intercambio afectivo", en el que el clientelismo se asienta en "redes informales existentes con anterioridad y en representaciones culturales compartidas" (Auyero, 2001: 29). Estas redes, dice, operan a través de mediadores políticos que "ofrecen incentivos solidarios a cambio de votos" (Guterbock en Auyero, 2001). Los mediadores, afirma Auyero, tienen casi siempre similares pertenencias de clase social con sus clientes, pero lo distintivo en ellos -dice- es su capital social derivado de sus conexiones y pertenencia a cierto grupo (Auyero, 2001: 104-105). En esta lógica, los votantes (clientes) son definidos como "agentes que dan apoyo político a un mediador/puntero o patrón a cambio de bienes, favores y servicios” (Auyero, 2001: 166).

El funcionamiento del clientelismo como mecanismo de expresión y procesamiento de las demandas sociales, señala Pachano (2007), opera al margen de la institucionalidad pero utilizándola de forma permanente. "Esta operación dentro y utilización de la institucionalidad", explica, "termina por erosionarla a causa de tres factores: 1) La necesidad de ofrecer respuestas inmediatas y puntuales 2) Los desajustes entre responsabilidades, acciones concretas y rendición de cuentas y 3 ) La informalización de la política" (Pachano, 2007: 110-111).

Las instituciones se ven obligadas a adecuarse a los objetivos, necesidades, prácticas y procedimientos que le son extraños y terminan por alterar su propia esencia. La formalidad institucional está para ser utilizada en función de intereses particulares (para proveer recursos, otorgar prebendas, retribuir favores e incluso como campo apropiado para prácticas corruptas) y no necesariamente para cumplir con las funciones establecidas. La normatividad formal debe coexistir con una institucionalidad real que tiene poco que ver con ella (Pachano, 2007: 111).

En este contexto, señala Pachano (2007), la relación política tiende a personalizarse en sus dos expresiones extremas; por un lado, "en la perspectiva de quienes conforman las redes clientelares poniendo por delante sus problemas y necesidades individuales"; y por otro, "en la perspectiva de quienes conducen esas redes y buscan imprimir su propio sello en cada una de éstas 
como garantía de permanencia y consolidación" (Pachano, 2007: 110). Este fenómeno provoca, dice, que los partidos y los políticos tengan una escasa definición ideológica, sobre todo en el ejercicio del poder.

Verdesoto (1984) sostiene que "la realidad política es compleja por la pluralidad de demandas, el particularismo de intereses sociales y políticos, y la crisis que inciden en la representación democrática a través de la corporativización de la demanda" (Verdesoto, 1984: 67).

Tanto los sectores empresariales como los sectores subalternos adquieren formas de expresión corporativizadas. Los primeros mediante las Cámaras Empresariales que actúan como grupos de presión a la gestión estatal (...). Los sectores subalternos también delinearon formas de presentación pública corporativizada. En lugar de profundizar la participación política que inicialmente fue electoral, los partidos se convirtieron en meros altavoces de las demandas corporativas (Verdesoto, 1984: 32).

Así, dice Verdesoto (1984), en los dos lados de la sociedad (cámaras empresariales y centrales sindicales) "se refugia la demanda expresamente clasista y los gremios han terminado corporativizando segmentos del aparato estatal (en lugar de) trasladar hacia el sistema político la demanda que inicialmente representan" (Verdesoto, 1984: 31).

Ospina (2010) explica que los intereses corporativistas han sido dominantes en el Ecuador y se expresan en dos arenas; por un lado, "pervierten a las organizaciones por la cooptación y manipulación del Estado"; y por otro, "contaminan de particularismos al Estado, borrando la búsqueda del bien común” (Ospina, 2010: 1-2).

El problema se ve agravado por la supervivencia de un sistema jurídico y de representación de intereses marcado por el sello de fuertes rasgos corporativistas que debilitan o distorsionan la separación entre interés particular y bien común. O bien el Estado manipula a las organizaciones en función de los intereses estatales, o bien las organizaciones manipulan al Estado en función de sus intereses particulares (Bustamante en Ospina, 2010: 2). 
El corporativismo produce, así, una "fractura entre necesidad, interés y representación" (Verdesoto, 1984) que hace del liderazgo (populista) "una figura que sustituye temporalmente las carencias y rearma precariamente el consenso acerca de la democracia a través de la oferta electoral" (Verdesoto, 1984: 34).

El análisis del populismo, el corporativismo y la cultura política que se expone en este trabajo deberá complementarse posteriormente con un estudio específico sobre el partidismo en la coyuntura analizada (2002-2020). Sin embargo, es necesario recordar que este fenómeno ha sido ampliamente estudiado, siendo paradigmáticos los trabajos de Freidenberg y Alcántara (2001) así como los aportes de Pachano (2007) y Sánchez (2008), entre otros.

Con fines meramente descriptivos entiendo al partidismo desde el planteamiento de Bustamante (2000), quien sugiere que en nuestro país los partidos son expresiones de culturas políticas y no simples organizaciones burocráticas. Para el caso ecuatoriano, plantea tres supuestos alternativos a los establecidos en la teoría normativa de los partidos políticos:

1) Las fronteras organizacionales de los partidos no coinciden con las fronteras de las prácticas, hábitos, valores y actitudes que en ellos encuentren expresión organizada (...) 2) Lo central no son los discursos, ideologías o plataformas de los partidos, sino las fórmulas pragmáticas que ellos encarnan (...). 3) La lucha partidista no representa una batalla entre aparatos sino es una confrontación entre mundos de sentido (...) (Bustamante, 2000: 89).

Los partidos como corrientes culturales, dice Bustamante (2000), "representan un tipo peculiar de organización de las costumbres que ligan a la gente en sus acciones frente al poder y en el poder" (Bustamante, 2000: 89). Desde esta perspectiva, asegura este autor, en Ecuador existen tres grandes partidos culturales: “1) Populismo cacical 2) Populismo estatista y 3) Modernismo tecnocrático cosmopolita (...) que pueden hallarse presentes de distintas maneras y en diferentes proporciones en los distintos aparatos partidistas" (Bustamante, 2000: 90) ${ }^{12}$.

12 Bustamante identifica a los siguientes partidos-culturales: 1) El roldosismo bucaramista y el social cristia- 
Esta situación, señala Bustamante (2010), hace que el partidismo en nuestro país sea incapaz de "realizar una continua superación de los intereses gremiales en la universalidad de la identidad partidista (...)", y por el contrario, se vea miméticamente sometido "al siempre permanente, florecimiento de la sociedad corporativa” (Bustamante, 2000, 96).

\section{Análisis de casos}

De los 41 años de vida democrática desde el retorno a ese régimen político en 1979, los últimos 18 se han sucedido cuatro gobiernos, dos de los cuales, fueron presididos por out-siders que llegaron de fuera del sistema de partidos, mientras que los dos restantes, se ejercieron por sus respectivos vicepresidentes, pero en circunstancias distintas ${ }^{13}$.

Este artículo compara tres de esos cuatro gobiernos y muestra cómo el populismo y el corporativismo dan origen a diferentes tipos de democracia que se expresan en culturas políticas diversas, que no necesariamente son "perjudiciales" para el conjunto del sistema político como se sugiere en buena parte de la literatura académica e incluso entre amplios sectores de la opinión pública (Hardt y Negri, 2004).

Lucio Gutiérrez (2002-2005) y Rafael Correa (2007-2017) tuvieron momentos fundacionales similares. Ambos llegaron al poder en su primera participación, convirtiendo a sus respectivos movimientos de acción electoral en partidos de gobierno (Quintero, 2002) y en sus inicios, capitalizaron los apoyos prácticamente de los mismos sectores sociales y políticos.

En el caso de Gutiérrez, además de Pachakutik y el Movimiento Popular Democrático (MPD) se produjo "una migración de adhesiones de centro

nismo (populismo cacical o patronal). 2) El populismo estatista que encuentra ciertas afinidades electivas en la izquierda sindical y parlamentaria y 3) El modernismo cosmopolita que se expresaba en ciertos sustratos de la Democracia Popular y por fuera de la política electoral en círculos académicos, de las Fuerzas Armadas y los organismos de la sociedad civil.

13 Gutiérrez fue reemplazado en 2005 por su vicepresidente Alfredo Palacio quien terminó el periodo del mandatario derrocado (2005-2006). Lenin Moreno fue vicepresidente de Correa entre 2007 y 2013 cuando fue reemplazado por Jorge Glas. En 2017, Moreno participó como candidato presidencial siendo Glas su binomio. Posteriormente al escándalo de corrupción de Odebrecht que llevó a la cárcel a Glas, le sucedió en el cargo María Alejandra Vicuña, separada también por corrupción y luego Otto Sonnenholzner, quien renunció el 07 de julio de 2020. Al momento de escribir este artículo se especula sobre su posible candidatura presidencial para las elecciones generales de 2021 . 
y de izquierda a través de una estrategia de movilización territorial y de concentraciones corporativo-territoriales" (Montúfar, 2004). En Correa, se concretó una "coalición heterogénea en torno a una clase media desencantada, estudiantes e intelectuales urbanos, partidos de izquierda, algunos sectores indígenas y movimientos sociales tanto de la Costa como de la Sierra" (Freidenberg, 2008: 224).

\section{Tabla 1}

\section{Aprobación presidencial y apoyo a la democracia}

\begin{tabular}{|c|c|c|c|c|c|c|c|}
\hline & \multicolumn{2}{|c|}{ Gutiérrez } & \multicolumn{3}{c|}{ Correa } & \multicolumn{2}{c|}{ Moreno } \\
\hline Años & $\mathbf{2 0 0 2}$ & $\mathbf{2 0 0 5}$ & $\mathbf{2 0 0 7}$ & $\mathbf{2 0 1 1}$ & $\mathbf{2 0 1 3}$ & $\mathbf{2 0 1 7}$ & $\mathbf{2 0 1 8}$ \\
\hline $\begin{array}{c}\text { Aprobación } \\
\text { Presidencial }\end{array}$ & 30 & 24 & 74 & 64 & 73 & 50 & 46 \\
\hline $\begin{array}{c}\text { Apoyo a la } \\
\text { democracia }\end{array}$ & 47 & 43 & 65 & 61 & 62 & 69 & 50 \\
\hline
\end{tabular}

Fuente: Informe Latinobarómero 1995-2015 e Informes Latinobarómetro 2017 y 2018/ Elaboración propia.

En la tabla 1 se relacionan dos variables medidas por el Latinobarómetro que sirven para mirar la imbricación que en el caso ecuatoriano existe entre el apoyo a la democracia y el liderazgo presidencial ${ }^{14}$.

Mientras en el caso de Gutiérrez y Moreno la aprobación presidencial es menor al apoyo a la democracia, en el periodo de Correa la relación es inversa, siendo la aprobación al primer mandatario superior a la otorgada al régimen político. Llama la atención, sin embargo, que en 2018, durante el segundo año de gobierno de Moreno, el apoyo a la democracia no supera el $50 \%$ y es apenas cuatro puntos porcentuales superior a la aprobación presidencial (46\%).

\footnotetext{
14 Hermann en Freidenberg (2008) explica varios tipos de liderazgo. a) Líder flautista de Hammelin, centrado en el líder, en sus cualidades personales, su seducción y su carisma. b) Líder vendedor, donde éste detecta los deseos, expectativas y necesidades de los seguidores y les hace ofertas acordes a ellos. c) Lider marioneta, que pone énfasis en los seguidores donde éste no es más que un instrumento del grupo y d) Líder bombero, que surge en un contexto de crisis y aparece cuando hay un problema para solucionarlo y luego desaparecer (Freidenberg, 2008: 193)
} 
Los datos muestran una correlación entre aprobación presidencial y respaldo a la democracia, que confirma la personalización de la política (Pachano, 2007) y la influencia del liderazgo en la democracia (Verdesoto, 1984) que en el caso de Correa creó una paradoja entre tecnocracia y populismo (De la Torre, 2015) y en el de Gutiérrez, dio origen a un populismo intermitente (Montúfar, 2014). En Moreno, en cambio, el apoyo a la democracia se reduce al 50\% siendo el porcentaje más bajo registrado por Latinobarómetro en 11 años (2007-2018), aunque es escasamente superior al registrado en el gobierno de Gutiérrez (2002-2005).

A diferencia del populismo que se manifiesta claramente en dos de los tres casos analizados aunque con distinta intensidad, el corporativismo se expresa en los tres pero de manera diferente. En el caso de Gutiérrez, se implementó en dos momentos. Primero, con la intención de cooptar a la CONAIE y fusionar al movimiento Pachakutik con el partido de gobierno ${ }^{15}$; y luego, para neutralizar en el Congreso Nacional un juicio político en su contra integrando un bloque parlamentario "Progresista" con el PRE, el PRIAN y diputados independientes ${ }^{16}$ (Montúfar, 2004) a cambio de reestructurar la Corte Suprema de Justicia para anular los juicios contra Abdalá Bucaram y permitir su retorno al país, como efectivamente ocurrió y fue un factor determinante para su derrocamiento.

Correa, en cambio, acudió permanentemente a las urnas para legitimar sus prerrogativas, generando una apropiación autoritaria de la voluntad popular (De la Torre, 2015) ${ }^{17}$ y al mismo tiempo desplegó una estrategia corporativista de relación con la sociedad (Ospina, 2010) caracterizada por cooptar y

\footnotetext{
15 El giro ideológico que dio Gutiérrez una vez en el cargo terminó -siete meses después del inicio de su mandato en 2002- la alianza que mantuvo con Pachakutik y el MPD. En el ejercicio del poder, el corporativismo estatal creó organizaciones paralelas a la Conaie como Fedepicne e incluso "fuerzas de choque" como el movimiento "Cero Corrupción".

16 Según Montúfar (2004) a cambio de apoyo, el PRIAN solicitó beneficios tributarios para las empresas de su líder Álvaro Noboa; el PRE, la anulación de los juicios contra su líder Abdalá Bucaram y los diputados independientes, puestos burocráticos locales para mantener sus bastiones electorales

17 En diez años de gobierno, el denominado proyecto de la Revolución Ciudadana triunfó en varios procesos electorales consecutivos, entre los que se incluyeron cuatro elecciones presidenciales (2006, 2009, 2013 y 2017); cuatro consultas populares y referéndum (2007, 2008, 2011 y 2017); elecciones a la Asamblea Constituyente (2007) que redactó una nueva Constitución; referéndum aprobatorio (2008) y elecciones seccionales (2009 y 2014).
} 
atacar a las organizaciones sociales y a ciertos sectores empresariales y mediáticos críticos de su gestión, acusándolos de intentar imponer sus intereses por sobre el interés general, que él decía representar ${ }^{18}$.

Durante el gobierno de Moreno, el corporativismo se expresó prácticamente desde el inicio de su mandato tras el giro ideológico y pragmático que dio el mandatario una vez en el poder (Burbano de Lara, 2017) y que se expresó en la designación de una parte de su gabinete ministeria ${ }^{19}$ llegando a consolidarse en una consulta popular (2018) que cambió gran parte de las autoridades del Estado $^{20}$, abriendo paso una transición política resultado de los siguientes factores:

a) Imposibilidad de relevar un liderazgo carismático y mesiánico al que se ató la trayectoria del proceso y la vida del movimiento b) La corrupción que llevó al enjuiciamiento penal y posterior encarcelamiento del vicepresidente Jorge Glas por el caso Odebrecht c) La desmitificación del legado de Correa y de la "década ganada" y d) Las divisiones, disputas y resentimientos entre facciones del movimiento (Burbano de Lara, 2017: 10).

18 Una característica que asumió este corporativismo estatal fue la creación de organizaciones paralelas "pro gobierno" en diferentes ámbitos como las dirigencias universitarias, los frentes de profesionales, los educadores y los sindicatos especialmente de los sectores estratégicos. Así surgieron, entre otras, la Red de Maestros de la Revolución Ciudadana que reemplazó a la UNE y la Central Unitaria de Trabajadores (CUT) que buscó imponerse al Frente Unitario de Trabajadores (FUT). En esta lógica uno de los casos emblemáticos fue el Decreto 16 mediante el cual se pretendió incorporar al Estado a varias organizaciones de la sociedad civil.

19 Aunque mantuvo algunos cuadros del correísmo colocó a figuras cercanas a diferentes sectores empresariales en varios ministerios como Pablo Campana (Comercio Exterior), Enrique Ponce (Turismo), Ana Drouet (Acuacultura), entre otros. Recuperado de https://www.elcomercio.com/pages/gabinete-lenin-moreno-experiencia-cuentas.html

20 Fiscal General del Estado, Procurador General, Consejo Nacional Electoral, entre los principales. Llama la atención que no se haya designado un nuevo Contralor General, entidad que está a cargo de Pablo Celi, ex sub-contralor de Carlos Pólit, quien fugó del país hacia Estados Unidos. 


\section{Tabla 2}

¿Para quién se gobierna?

\begin{tabular}{|c|c|c|c|c|c|}
\hline & Gutiérrez & \multicolumn{2}{|c|}{ Correa } & \multicolumn{2}{c|}{ Moreno } \\
\hline Años & $\mathbf{2 0 0 2 - 2 0 0 5}$ & $\mathbf{2 0 1 3}$ & $\mathbf{2 0 1 5}$ & $\mathbf{2 0 1 7}$ & $\mathbf{2 0 1 8}$ \\
\hline Gobierna para el pueblo & 11 & 62 & 56 & 38 & 17 \\
\hline$(2005)$ & 87 & 36 & 42 & 58 & 81 \\
\hline $\begin{array}{c}\text { Gobierna para grupos poder- } \\
\text { osos en su propio beneficio }\end{array}$ & $(2005)$ & & & & \\
\hline
\end{tabular}

Fuente: Informe Latinobarómetro 1995-2015. Informe Latinomarómetro 2017 y 2018: Elaboración propia.

La tabla 2 muestra que en el gobierno de Gutiérrez y en el de Moreno, la población percibe que se gobernó más para intereses corporativistas (Pachano, 2007) que para "todo el pueblo". En 2013, al inicio del último mandato de Correa (2013-2017), en cambio, los encuestados tuvieron la percepción contraria. Sin embargo, en 2015, esa percepción cayó 6 puntos del 62 al $56 \%$, aumentando casi hasta el 50\% la percepción que Correa gobernaba para grupos poderosos.

Un ejemplo coyuntural del corporativismo en el gobierno de Moreno es la recientemente vigente Ley de Apoyo Humanitario por el Covid-19, donde el Ejecutivo -por presión de grupos empresariales cercanos al movimiento CREO- retiró todo un capítulo de ese proyecto (tabla de contribución de acuerdo al nivel de ingresos) para lograr los apoyos necesarios en la Asamblea Nacional y aprobar esa normativa ${ }^{21}$.

21 Sumado a esto, el Gobierno ha iniciado un claro proceso de ajuste estructural de la economía, acorde con una carta de intención suscrita con el Fondo Monetario Internacional (FMI) que implica entre otras cosas, la reducción del tamaño del Estado vía despidos y baja de salarios, así como la liberalización del precio de los combustibles. Estas medidas se adhieren a la intención de reducir el presupuesto para las universidades públicas y todas juntas han configurado un nuevo escenario de conflictividad social que por el confinamiento derivado de la pandemia del Covid19 no ha alcanzado los niveles del paro nacional y levantamiento indígena de octubre de 2019. 


\section{Tabla 3}

\section{Tipología de la democracia}

\begin{tabular}{|c|c|c|c|c|}
\hline Gobiernos & $\begin{array}{c}\text { Corporati- } \\
\text { vismo }\end{array}$ & Populismo & Partidismo & $\begin{array}{c}\text { Tipo de demo- } \\
\text { cracia }\end{array}$ \\
\hline Lucio & SI & SI & SI & $\begin{array}{c}\text { Pseudopopulista, } \\
\text { partidista-corpo- } \\
\text { rativista }\end{array}$ \\
\hline Gutiérrez & SI & SI & NO & $\begin{array}{c}\text { Populista-corpo- } \\
\text { rativista anti-par- } \\
\text { tidista }\end{array}$ \\
\hline Lenin Moreno & SI & NO & SI & $\begin{array}{c}\text { Corporativis- } \\
\text { ta-partidista }\end{array}$ \\
\hline
\end{tabular}

Fuente: Revisión bibliográfica citada en este artículo/ Elaboración propia.

La tabla 3 propone que los casos analizados -que cronológicamente responden a los últimos 18 años de vida democrática- producen un particular tipo de democracia toda vez que tanto el corporativismo como el populismo se relacionan con un tercer aspecto: el partidismo entendido en este artículo como expresión de diversas culturas políticas (Bustamante, 2000).

El tipo de democracia pseudopopulista, partidista, corporativista del gobierno de Gutiérrez (2002-2005) se caracteriza por el uso del populismo como estrategia (De la Torre, 2008) en la campaña electoral de 2002, pero en el ejercicio del poder se convirtió en un gobierno partidista y corporativista en la medida en que concretó alianzas el PRE y el PRIAN, mientras que profundizó su estrategia de cooptación a los movimientos sociales mediante la creación de organizaciones paralelas, que sin embargo, no pudieron sostenerlo en el poder, precipitando su derrocamiento en 2005.

La caída de Gutiérrez (2005) con la consigna “fuera todos" marcó un punto de inflexión en la democracia ecuatoriana que tuvo como desenlace el colapso del sistema de partidos cuando Rafael Correa asumió el poder (2007) con la promesa refundacional de instalar una Asamblea Constituyente, como efectivamente sucedió. Ya en el poder, Correa implementó una democracia populista-corporativista anti-partido, que se caracterizó por mantener y legitimar el antagonismo (Laclau, 2005) entre el "pueblo" que decía encarnar 
Correa y la "partidocracia", así como por cooptar a la sociedad creando -al igual que Gutiérrez- organizaciones paralelas, expidiendo un decreto para regularlas e incluyendo a dirigentes de históricos sectores corporativistas como los de la transportación pública en sus listas de candidatos ${ }^{22}$.

Esta estrategia funcionó en términos de gobernabilidad en la medida en que Correa ha sido el único presidente en la historia del Ecuador (desde 1830) en permanecer diez años consecutivos en el poder con un nítido apoyo popular, lo que abre una interrogante general que supera el análisis exclusivo de ese gobierno y ha sido ya esbozada bajo el atrayente calificativo de "democracia populista"23.

En el caso de Moreno (2017-2020) se implementa una democracia corporativista-partidista que se tradujo en un giro ideológico y pragmático (Burbano de Lara, 2017) hacia las posiciones de los partidos políticos y sectores de oposición al correísmo, así como por un ejercicio del poder marcado por la imposición de intereses corporativistas de distintos grupos que se expresan en agendas específicas ya citadas en este artículo.

\section{Conclusiones}

- Los "ismos" de la democracia en Ecuador superan las definiciones mínimas con las que generalmente se tiende a conceptualizar este régimen político. Por el contrario, populismo y corporativismo representan manifestaciones concretas, culturas políticas específicas que dotan de sentido a la democracia ecuatoriana al menos en los últimos 18 años, lo que hace necesario enfrentar este dilema re-conceptualizando el régimen político, con el objetivo de perfilar su rostro más auténtico con el objetivo de

22 Correa utilizó el término "partidocracia" para dotarlo de un contenido distinto al histórico y referirse a los sectores de oposición a su gobierno como los partidos tradicionales y los medios de comunicación. El correísmo creó organizaciones paralelas en distintos ámbitos a las denominadas "históricas" como la UNE, el FUT y la FEUE que fueron divididas con la creación de la Red de Maestros, la CUT y otra FEUE emitiendo el Decreto 016 para regularlas. Los dirigentes de la transportación Pedro Zapata y Alberto Arias fueron asambleístas por Alianza PAIS.

23 Burbano de Lara (2019) explica que "en la política ecuatoriana, el poder constituido, que expresa el ideal liberal del Estado de derecho, convive con el poder constituyente, que expresa, en cambio, el ideal de movilización populista del pueblo. Conviven, se imbrican, cohabitan, en lugar de diferenciarse. No es, como usualmente creemos, que el populismo asalta la democracia en ciertas coyunturas para dañarla. Hay una infiltración permanente del populismo sobre la democracia". 
superar los "lugares comunes" que reducen la democracia únicamente al esporádico ejercicio del sufragio, la defensa de la libertad de expresión y la independencia de poderes, etc.

- Populismo y corporativismo no son fenómenos antagónicos o mutuamente excluyentes sino que incluso pueden expresarse (complementarse) de diversas formas en un mismo gobierno dando lugar a diferentes tipos de democracia. Mientras el corporativismo es rechazado por la población al punto de provocar crisis políticas que como en el caso de Gutiérrez (2005) desembocaron en su derrocamiento, o en el de Moreno (2019) generaron una explosión social sin precedentes, el populismo parecería ser una forma genuina de la democracia en nuestro país al menos en los últimos 18 años, contrariamente a lo que considera gran parte de la literatura académica.

- Estos dos fenómenos (populismo y corporativismo) se despliegan en manifestaciones específicas sincréticas y no necesariamente contradictorias según cada caso analizado. En Gutiérrez, el populismo se expresó como una estrategia política durante la campaña electoral de 2002, mientras en Correa fundamentalmente como un discurso durante toda su administración (2007-2017). En ambos gobiernos, el corporativismo funcionó desde el Estado como un instrumento de cooptación de la sociedad. En el gobierno de Moreno, en cambio, desaparece el populismo y se consolida el corporativismo pero ya no desde el Estado sino desde grupos de presión que marcan la agenda del Ejecutivo.

- En Ecuador hay una correlación entre aprobación presidencial y apoyo a la democracia, lo que hace que para los ciudadanos, el liderazgo político sea una condición necesaria para el "adecuado" funcionamiento de la democracia y no a la inversa. La democracia per sé no funciona sin liderazgo. La comparación entre los gobiernos de Gutiérrez, Correa y Moreno refleja que la democracia en el periodo analizado tiende a fortalecerse con el populismo y a debilitarse con el corporativismo-partidismo. 
- Las culturas políticas si bien se diferencian regional y étnicamente tienden en el Ecuador a implementar una lógica política común caracterizada por la resolución de problemas como empleo, salud, seguridad, etc. Esto provoca que la democracia se vista de contenidos concretos que deben satisfacerse para una ciudadanía distinta a la imaginada en las teorías normativas y que no se agota en el sufragio, ni en las permanentes reformas institucionales al sistema político, que generalmente buscan contener y/o eliminar al populismo, pero curiosamente, no abordan o incluso promueven el corporativismo. 


\section{Bibliografía}

Andrade, P. (2009). Democracia y cambio político en el Ecuador. Liberalismo, política de la cultura y reforma institucional. Quito: Corporación Editora Nacional.

Andrade, P. (2003). “El imaginario democrático en el Ecuador”. En F. Burbano de Lara (Comp.), Antología Democracia, gobernabilidad y cultura política. Quito: Flacso-Ecuador.

Auyero, J. (2001). La política de los pobres. Las prácticas clientelistas del peronismo. Buenos Aires: Manantial.

Burbano de Lara, F. (2019, 20 de agosto). "Democracia populista". El Universo. Recuperado de https://www.eluniverso.com/opinion/2019/08/20/ nota/7478844/democracia-populista

Burbano de Lara, F. (2017). "Parricidas, leales y traidores. La dramática transición ecuatoriana hacia el poscorreísmo". En H. Ibarra (Ed.), Ecuador Debate No. 102. Quito: Centro Andino de Acción Popular (CAAP).

Burbano de Lara, F. (1998). Cultura política y democracia en el Ecuador: una aproximación a nuestros vacios. Quito: Corporación de Estudios para el Desarrollo (Cordes)

Bustamante, F. (2006). "Sociedad civil y partidos: más allá del corporativismo". En Revista Entre Voces No. 5. Quito: Grupo Democracia y Desarrollo Local (GDDL).

Bustamante, F. (2000). "Los partidos y los alineamientos políticos como culturas”. En Revista Íconos No. 9. Quito: Flacso-Ecuador.

Bustamante, F. (1997). "Una aproximación a los problemas de la gobernabilidad y la democracia en el Ecuador de fin de milenio". En Revista Ecuador Debate No. 42. Quito: Centro Andino de Acción Popular (CAAP). 
Corporación Latinobarómetro (2018). Informe 2018. Quito. Instituto de la Democracia IDD-CNE. Recuperado de file:///C:/Users/cliente/Desktop/ IDD-CNE/LATINOBAROMETRO\%202018.pdf

Corporación Latinobarómetro (2017). Informe 2017. Buenos Aires. Instituto de la Democracia IDD-CNE. Recuperado de file:///C:/Users/cliente/ Desktop/IDD-CNE/Latinobarometro\%202017.pdf

Corporación Latinobarómetro Opinión Pública Latinoamericana (2015). Informe 1995-2015. Santiago de Chile. Instituto de la Democracia IDD-CNE. Recuperado de file:///C:/Users/cliente/Desktop/IDD-CNE/LATINOBAROMETRO\%201995-2015.pdf

De la Torre, C. (2015). De Velasco a Correa. Insurrecciones, populismos y elecciones en Ecuador, 1944-2013. Quito: Corporación Editora Nacional.

De la Torre, C. (2008). "Populismo, ciudadanía y Estado de Derecho". En C. De la Torre y E. Peruzzotti (Eds.), El retorno del pueblo. Populismo y nuevas democracias en América Latina. Quito: Flacso-Ecuador.

Freidenberg, F. (2008). "El Flautista de Hammlin: Liderazgo y populismo en la democracia ecuatoriana". En C. De la Torre y E. Peruzzotti (Eds.), El retorno del pueblo. Populismo y nuevas democracias en América Latina. Quito: Flacso-Ecuador.

Freidenberg, F. (2003). Jama, caleta y camello: Las estrategias de Abdalá Bucaram y el PRE y para ganar las elecciones. Quito: Corporación Editora Nacional.

Freidenberg, F. y Alcántara M. (2001). Los dueños del poder. Los partidos políticos en Ecuador. Quito: Flacso-Ecuador.

Hardt, R. y Negri, A. (2004). Multitud. Guerra y democracia en la era del Imperio. Buenos Aires: Debate. 
Laclau, E. (2005). La razón populista. Buenos Aires: Fondo de Cultura Económica.

Menéndez, A. (1986). La conquista del voto en el Ecuador: de Velasco a Roldós. El Suburbio Guayaquileño en las Elecciones Presidenciales 1958-1978. Análisis del comportamiento electoral a nivel local en un contexto de control social. Quito: Corporación Editora Nacional.

Moncayo, P. (2008). Veintiocho de Mayo de 1944. Una democracia fallida. Quito: Abya-Yala.

Montúfar, C. (2004). "El populismo intermitente de Lucio Gutiérrez”. Quito: Flacso-Ecuador. Recuperado de https://biblio.flacsoandes.edu. ec/catalog/resGet.php?resId=24686

Ospina, O. (2010). "Corporativismo, Estado y Revolución Ciudadana”. Quito: Instituto de la Democracia IDD-CNE. Recuperado de file:///C:/Users/ cliente/Desktop/IDD-CNE/CORPORATIVISMO, $\% 20$ OSPINA.pdf

Pachano, S. (2007). La trama de Penélope. Procesos políticos e Instituciones en el Ecuador. Quito: IDEA Internacional-Flacso-Ecuador.

Paz y Miño, J. (2002). Golpe y contragolpe. La rebelión de Quito del 21 de enero del 2000. Quito: Abya-Yala.

Quintero, R. y Sylva, E. (2013). Ecuador: una nación en ciernes. Quito: Abya-Yala.

Quintero, R. y Sylva, E. (2010). "Ecuador: La alianza de la derecha y el corporativismo en el "putch" del 30 de septiembre del 2010". En M. Mancero (Comp.), 30S: La Contrarrevolución. Quito: Ministerio Coordinador de la Política y Gobiernos Autónomos Descentralizados.

Quintero, R. (2002). Entre el hastio y la participación ciudadana. Partidos y elecciones en el Ecuador (2000-2002) Quito: Abya-Yala.

Ramírez, F. (2003). "Explorando en un agujero negro. Apuntes para una crítica de las visiones dominantes sobre cultura política en el Ecuador”. En F. Burbano de Lara (Comp.), Antología Democracia, gobernabilidad y 
cultura política. Quito: Flacso-Ecuador.

Sánchez, F. (2008). ¿Democracia no lograda o democracia malograda? Un análisis del sistema político del Ecuador: 1979-2002. Quito: Flacso-Ecuador.

Torres, R. (2016). "Perspectiva de la teoría de clivajes para el caso latinoamericano". En Cuadernos Americanos No. 155. México: UNAM. Recuperado de http://www.cialc.unam.mx/cuadamer/textos/ca155-97.pdf

Ulloa, C. (2017). El populismo en escena. ¿Por qué emerge en unos países y en otros no? Quito: Flacso-Ecuador.

Verdesoto, L. (1984). "La primera vuelta presidencial: Análisis político de sus resultados". En L. Verdesoto (Comp.), 1984: El Ecuador en las urnas. Lucha Social. Lucha Política. Quito: El Conejo-Fundación Naumann.

Verdesoto, L. (1984) "El conflicto principal de la actual coyuntura". En L. Verdesoto (Comp.), 1984: El Ecuador en las urnas. Lucha Social. Lucha Política. Quito: El Conejo-Fundación Naumann. 